\title{
Splenic rupture after videothoracoscopic procedure: An unusual complication conservatively managed
}

\author{
Sergio Nicola Forti Parri, MD, ${ }^{\mathrm{a}}$ Gian Marco Guiducci, MD, ${ }^{\mathrm{a}}$ Andrea Domanico, MD, ${ }^{\mathrm{b}}$ and \\ Gregorio Tugnoli, MD, ${ }^{\mathrm{c}}$ Bologna, Italy
}

Splenic rupture after videothoracoscopic lung procedures is a very rare event. We report a case in which conservative management including embolization therapy provided effective treatment.

\section{CASE REPORT}

A 51-year-old patient was admitted to our unit after the incidental detection of a pleural mass (pleural solitary fibrous tumor) during radiologic examinations for impacted urolithiasis. The patient underwent video-

From the Thoracic Surgery Unit, ${ }^{\text {a }}$ Presidio Ospedaliero Maggiore-Bellaria, Bologna, Italy; the Ultrasound Center, ${ }^{\mathrm{b}}$ Internal Medicine A, Maggiore Hospital, Bologna, Italy; and the Department of Emergency Surgery, ${ }^{\mathrm{c}}$ Maggiore Hospital, Bologna, Italy.

Disclosures: Authors have nothing to disclose with regard to commercial support. Received for publication June 7, 2014; revisions received July 27, 2014; accepted for publication Aug 1, 2014; available ahead of print Aug 26, 2014.

Address for reprints: Sergio Nicola Forti Parri, MD, Thoracic Surgery Unit, Presidio Ospedaliero Maggiore-Bellaria, Largo Nigrisoli 2, Bologna, Italy (E-mail: sergionicola.fortiparri@ausl.bo.it).

J Thorac Cardiovasc Surg 2014;148:e236-7

$0022-5223 / \$ 36.00$

Copyright (C) 2014 by The American Association for Thoracic Surgery

http://dx.doi.org/10.1016/j.jtcvs.2014.08.004 assisted thoracoscopic resection of the pleural mass under general anesthesia. Surgery only lasted 21 minutes and was uneventful. The tumor was resected with a single stapler fire and extracted within an endobag. Chest drainage was removed on postoperative day 1 .

Results of chest radiography performed before discharge on postoperative day 2 were unremarkable, but the hemoglobin level dropped to $8.0 \mathrm{~g} / \mathrm{dL}$ from a preoperative level of $14.1 \mathrm{~g} / \mathrm{dL}$. Physical examination of the chest did not show significant findings, and the abdomen was soft with mild tenderness on deep palpation. The patient passed normal stools after surgery. A repeated check of hemoglobin level after 4 hours confirmed the significant hemoglobin drop to $7.6 \mathrm{mg} / \mathrm{dL}$; nonetheless, the patient was in hemodynamically stable condition.

Abdominal computed tomographic scan was requested and showed a $13 \times 6$-cm subcapsular hemorrhage of the spleen with moderate amount of free intraperitoneal fluid. We decided on a nonoperative treatment and proceeded to perform angiography with embolization of the spleen. The procedure was uneventful, and the ensuing radiographic examinations (upper abdomen contrast-enhanced

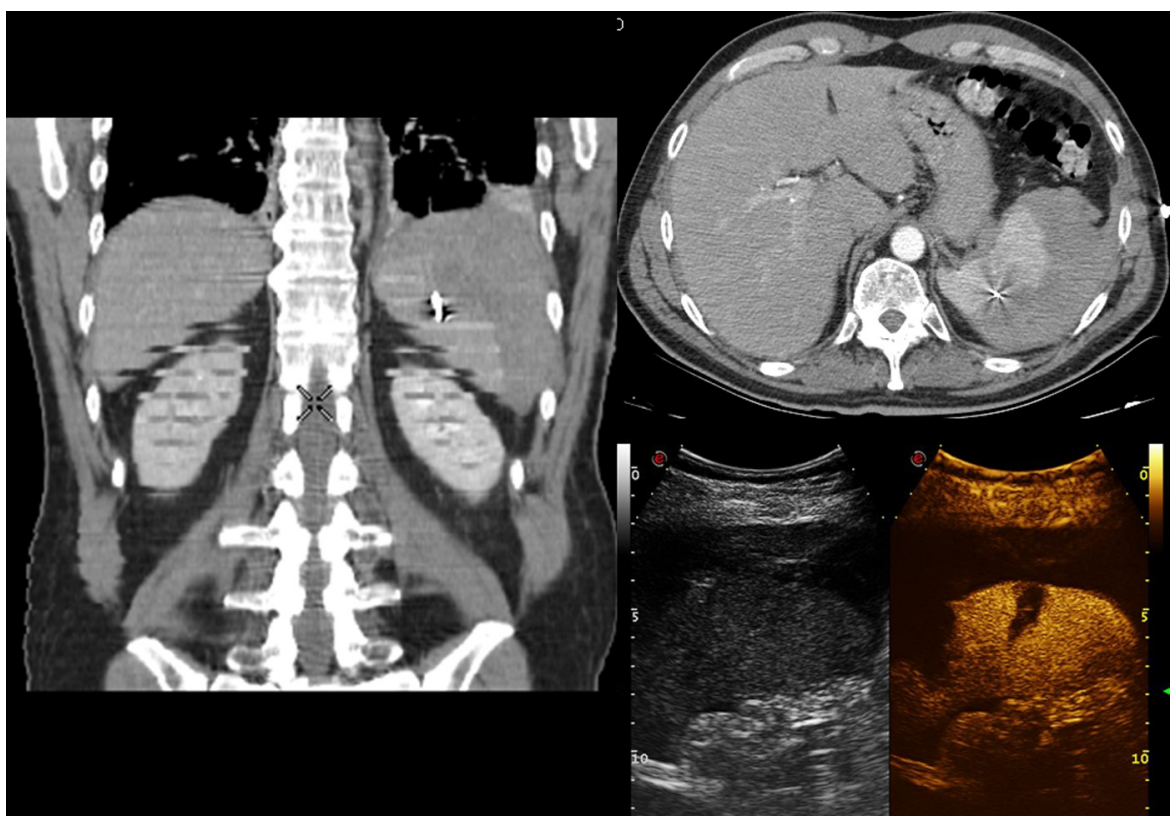

FIGURE 1. Computed tomographic and echocardiographic controls show stability of the subcapsular hematoma with no active sources of bleeding. 
ultrasonography ${ }^{1}$ and abdominal computed tomography) showed no changes in the subcapsular hematoma with no active sources of bleeding (Figure 1). After a few days of observation in the hospital, the patient was discharged and followed up as an outpatient, with repeated follow-up abdominal ultrasonography showing normal resolution of the hematoma.

\section{DISCUSSION}

Splenic rupture after videothoracoscopic lung procedures is a very rare event. In the only case previously described in the literature, ${ }^{2}$ an emergency splenectomy was required after a splenic injury occurred during video-assisted pulmonary resection of a nonmalignant tumor. The suggested cause of injury was a transdiaphragmatic blunt trauma with intact diaphragm.

In our case we did not detect any direct evidence of a laceration of the diaphragm at the end of the videothoracoscopic procedure, and the ensuing radiographic examinations also yielded negative results. Transdiaphragmatic blunt trauma to the spleen was clearly caused by the positioning of one of the thoracoscopic ports (the lowest was inserted in the ninth intercostal space posteriorly) or by the insertion of the mechanical suture device (we have used the lowest one for the stapler), which can be troublesome if the pulmonary lesions are in close proximity to the chest wall.
Our trauma center experience suggests that conservative treatment was the ideal choice, particularly in managing a blunt trauma to parenchymal ${ }^{3}$ organs, for which angiographic arterial embolization is the preferred solution. ${ }^{4,5}$

In conclusion, splenic injuries occurring during thoracic surgery procedures may be safely managed conservatively in the presence of hemodynamic stability. Transdiaphragmatic insults to the spleen are likely to be single and localized and thus easy to control with an endovascular arterial embolization. Splenectomy should be the last viable option when conservative treatment fails or in case of sudden hemodynamic instability.

\section{References}

1. Cagini L, Gravante S, Malaspina CM, Cesarano E, Giganti M, Rebonato A, et al Contrast enhanced ultrasound (CEUS) in blunt abdominal trauma. Crit Ultrasound J. 2013;5(Suppl 1):S9.

2. Flores RM, Thekweazu U, Dycoco J, Rizk NP, Rusch VW, Bains MS, et al Video-assisted thoracoscopic surgery (VATS) lobectomy: catastrophic intraoperative complications. J Thorac Cardiovasc Surg. 2011;142:1412-7.

3. Peitzman AB, Heil B, Rivera L, Federle MB, Harbrecht BG, Clancy KD, et al. Blunt splenic injury in adults: Multi-Institutional Study of the Eastern Association for the Surgery of Trauma. J Trauma. 2000;49:177-87.

4. Di Saverio S, Giorgini E, Biscardi A, Sibilio A, Villani S, Naidoo N, et al. Surgical treatment of spleen trauma. In: Di Saverio S, Tugnoli G, Catena F, Ansaloni L, Naidoo N, eds. Trauma surgery: volume 2: thoracic and abdominal trauma. Milan: Springer Italia; 2014:117-34.

5. Bhullar IS, Frykberg ER, Siragusa D, Chesire D, Paul J, Tepas JJ III, et al Selective angiographic embolization of blunt splenic traumatic injuries in adults decreases failure rate of nonoperative management. J Trauma Acute Care Surg. 2012;72:1127-34.

\title{
Pyomyositis of the chest wall presenting with empyema thoracis
}

\author{
Olusola Oduntan, MD, FACS, ${ }^{a}$ and Arif R. Sarwari, MD, MSc, MBA, ${ }^{\mathrm{b}}$ Morgantown, WVa
}

Pyomyositis is an inflammatory condition of the skeletal muscle. It was first described by Scriba in 1885 as a disease endemic to the tropics, hence the term tropical pyomyositis. Until recently, pyomyositis was considered unusual in the temperate zone. ${ }^{1,2}$ Although any skeletal muscle may be involved, pyomyositis has

\footnotetext{
From the Division of Thoracic Surgery, ${ }^{\mathrm{a}}$ Department of Surgery, and the Section of Infectious Disease, ${ }^{b}$ Department of Medicine, West Virginia University, Morgantown, WVa.

Disclosures: Authors have nothing to disclose with regard to commercial support. Received for publication March 6, 2014; revisions received June 13, 2014; accepted for publication July 12, 2014; available ahead of print Aug 26, 2014.

Address for reprints: Olusola Oduntan, MD, FACS, PO Box 957, Morgantown, WV 26507 (E-mail: solaodunt@aol.com).

J Thorac Cardiovasc Surg 2014;148:e237-9

$0022-5223 / \$ 36.00$

Copyright (C) 2014 by The American Association for Thoracic Surgery

http://dx.doi.org/10.1016/j.jtcvs.2014.07.092
}

predilection for large muscle masses of the body. Multiple muscle involvement occurs in $12 \%$ to $60 \%$ of patients.

There are 3 stages of presentation. The first stage is the "invasive stage," with minimal signs of inflammation. There may be muscle pain, fever, and mild leukocytosis. The second stage is the "suppurative stage," between 10 and 20 days from the onset of symptoms. Signs of inflammation are more pronounced, with swelling, tenderness, and fever. Needle aspiration yields purulent exudate. The final stage is the "septicemic stage," when the patient is acutely ill, with high fever and toxicity. Occasionally, septicemia and coma may be seen.

Computed tomographic (CT) scan and magnetic resonance imaging are the best imaging techniques for early diagnosis and follow-up of the patient. 